\title{
Displaying a recombinant protein on flocs self-produced by Escherichia coli through fused expression with elongation factor Ts
}

Yoshihiro Ojima, Shota Nunogami, Masayuki Azuma, Masahito Taya

\begin{tabular}{|c|l|}
\hline Citation & Enzyme and Microbial Technology, 108: 21-25 \\
\hline Issue Date & $2018-01$ \\
\hline Type & Journal Article \\
\hline Textversion & author \\
\hline \multirow{3}{*}{ Rights } & $\begin{array}{l}\text { C } 2017 \text { Elsevier Inc. This manuscript version is made available under the } \\
\text { CC-BY-NC-ND 4.0 License. } \underline{\text { http://creativecommons.org/licenses/by-nc-nd/4.0/ }} \cdot \\
\text { This is the accept manuscript version. The article has been published in final form at } \\
\text { https://doi.org/10.1016/j.enzmictec.2017.08.010 }\end{array}$ \\
\hline DOI & \begin{tabular}{l} 
10.1016/j.enzmictec.2017.08.010 \\
\hline
\end{tabular} \\
\hline
\end{tabular}

\author{
Self-Archiving by Author(s) \\ Placed on: Osaka City University
}

OJIMA, Y., NUNOGAMI, S., AZUMA, M., \& TAYA, M. (2018). Displaying a recombinant protein on flocs self-produced by Escherichia coli through fused expression with elongation factor Ts. Enzyme and Microbial Technology. 108, 21-25. 
Displaying a recombinant protein on flocs self-produced by Escherichia coli through fused expression with elongation factor

Ts

Yoshihiro Ojima $^{1 *}$, Shota Nunogami ${ }^{2}$, Masayuki Azuma ${ }^{1}$ and Masahito Taya ${ }^{2}$

${ }^{1}$ Department of Applied Chemistry and Bioengineering, Graduate School of Engineering, Osaka City University, 3-3-138, Sugimoto, Sumiyoshi-ku, Osaka 558-8585, Japan

${ }^{2}$ Division of Chemical Engineering, Graduate School of Engineering Science, Osaka University, 1-3 Machikaneyama-cho, Toyonaka, Osaka 560-8531, Japan

* Corresponding author: Yoshihiro Ojima

Tel.: +81-6-6605-2163

Fax: +81-6-6605-3092

E-mail: ojima@bioa.eng.osaka-cu.ac.jp

Keywords: floc engineering; Escherichia coli; protein display; $t s f$ 
Highlights

We demonstrated expression of a fusion protein consisting of Tsf and GFP on E. coli flocs.

The percentage of Tsf-GFP in total floc protein reached approximately $15 \%(\mathrm{w} / \mathrm{w})$.

This technique could display heterologous protein on the $E$. coli floc structure. 


\section{ABSTRACT}

2 The utility of engineering flocculation is wildly recognized in applied and 3 environmental microbiology. We previously reported self-produced flocculation of 4 Escherichia coli cells by overexpressing the native $\operatorname{bcs} B$ gene that encodes a component 5 of the cellulose synthesis pathway. Further experiments clarified that the spontaneous $E$. 6 coli flocs were proteinous, and elongation factor Ts (Tsf) was the main component. In 7 this study, we demonstrated successful expression of a fusion protein consisting of Tsf 8 and green fluorescence protein (GFP) on E. coli flocs. Interestingly, the percentage of 9 Tsf-GFP in total floc protein reached approximately $15 \%(\mathrm{w} / \mathrm{w})$. The proposed design of 10 a fusion protein with Tsf enables displaying a recombinant target protein on the floc 11 structure. 
Flocculation is an aggregation phenomenon of bacterial cells in the form of flocs or

3 flakes. Numerous microorganisms have been found to show floc-forming capabilities

4 [1] that can be applied to wastewater treatment. In activated sludge, the components of

5 flocs typically include polysaccharides, polynucleotides, and proteins [2]

6 Escherichia coli is a typical laboratory microbe that lacks the floc-forming ability.

$7 \quad$ Many researches have attempted to induce floc formation of $E$. coli by adding artificial

8 flocculants consisting of inorganic compounds including aluminum and cationic

9 polymers such as chitosan [3-5]. We have previously reported self-produced

10 flocculation of $E$. coli cells by overexpressing the native $\operatorname{ccs} B$ gene [ $\underline{6}$ ] that encodes a

11 component of transmembrane cellulose synthase [7]. Further experiments clarified the spontaneous E. coli flocs were proteinous, and elongation factor Ts (Tsf) had the highest score among floc proteins in nano-liquid chromatography-tandem mass spectrometry (LC-MS/MS) analysis []]. Tsf is known to promote the release of GDP by forming an intermediate complex with another elongation factor, $\mathrm{Tu}$, which is involved in the elongation cycle of protein biosynthesis [9]. These results promoted us to evaluate Tsf for displaying a heterologous protein on the proteinous structure of self-produced E. coli flocs.

19 In this study, we designed a fusion protein consisting of Tsf and green fluorescence 20 protein (GFP), which was expressed during the process of E. coli floc formation. 21 Observations of GFP revealed localization of Tsf protein within the floc structure. Furthermore, quantitative evaluation based on western blotting was conducted to determine the amount of fusion protein throughout the floc structure. 
MATERIALS AND METHODS

2

3

4

5

\section{Bacterial strains and media}

The bacterial strains and plasmids used in this study are listed in Table 1. E. coli $\mathrm{K}-12$ strain BW25113 was obtained from the National BioResource Project (National Institute of Genetics (NIG), Mishima, Japan) [10]. The pNTR-SD-bcsB plasmid [11] was provided by NIG and the transformant was named BW25113/bcs $B$ that forms spontaneous flocs []]. pCA24N and ASKA-tsf-gfp plasmids were also provided by NIG [12]. To express GFP, the pCA24N-gfp plasmid was constructed from pCA24N by adjusting the $g f p$ gene in frame [12]. BW25113/bcsB cells were transformed with pCA24N-gfp and ASKA-tsf-gfp plasmids and the resultant strains were named BW25113/bcsB/gfp and BW25113/bcsB/tsf-gfp, respectively.

E. coli cells were cultured in lysogeny broth (LB) medium (10 g/L Hipolypeptone, 5 $\mathrm{g} / \mathrm{L}$ Bacto-yeast extract and $10 \mathrm{~g} / \mathrm{L} \mathrm{NaCl}$ ). The culture medium for strains harboring the plasmids contained with $50 \mathrm{mg} / \mathrm{L}$ ampicillin or $25 \mathrm{mg} / \mathrm{L}$ chloramphenicol. All test cultures were precultured in LB medium for $14 \mathrm{~h}$ at $37^{\circ} \mathrm{C}$ and then inoculated into L-tubes containing fresh LB medium with $2 \mathrm{~g} / \mathrm{L}$ glucose (LB-G) giving an optical density of $660 \mathrm{~nm}\left(\mathrm{OD}_{660}\right)=0.01$.

\section{Flocculation of each $E$. coli strain}

For floc formation, E. coli cells were cultured in $10 \mathrm{~mL} \mathrm{LB}-\mathrm{G}$ medium at $37^{\circ} \mathrm{C}$ in an L-tube with shaking at 45 strokes/min. The recombinant strains were cultured in medium containing isopropyl $\beta$-D-1-thiogalactopyranoside (1 $\mathrm{mM})$, ampicillin (50 $\mathrm{mg} / \mathrm{L})$ and chloramphenicol (25 mg/L). After $24 \mathrm{~h}$ of culture, the L-tubes containing the floc and cell suspension were left to stand at room temperature for $15 \mathrm{~min}$ and the 
resultant precipitates were resuspended in a $0.9 \%(\mathrm{w} / \mathrm{v}) \mathrm{NaCl}$ solution. The resultant flocs were transferred into glass bottles and photographed using a digital camera under irradiation by fluorescent light or black light (peak wavelength; $365 \mathrm{~nm}$ ) lamp to confirm GFP expression. For quantitative assays, the resultant flocs were washed four times with the $0.9 \%(\mathrm{w} / \mathrm{v}) \mathrm{NaCl}$ solution to remove loosely adsorbed cells on the flocs.

The amount of protein in the flocs was measured by a Pierce ${ }^{\mathrm{TM}}$ BCA protein Assay Kit

(Thermo Fisher Scientific Inc., UK) and the value was used as an index of floc amount as described previously [13]. The number of E. coli cells included in the floc structure was estimated by measuring ATP as described elsewhere [13]. ATP measurement was conducted using an ATP Colorimetric/Fluorometric Assay Kit (BioVision Inc., Milpitas, CA) according to the manufacturer's procedure.

\section{Microscopic observation of flocs}

Flocs were observed under an inverted Eclipse Ti microscope with NIS-Elements Advanced Research software (Nikon Corp., Japan). Prior to analysis, the flocs were fixed with $2.5 \%(\mathrm{v} / \mathrm{v})$ glutaraldehyde for $1 \mathrm{~h}$. After washing, DNA of E. coli cells in the floc structure was stained with $20 \mathrm{mg} / \mathrm{L}$ propidium iodide (PI) by incubation for $30 \mathrm{~min}$ in the dark. The samples were observed under sequential excitation at wavelengths of 488 and $561 \mathrm{~nm}$.

Sodium dodecyl sulfate-polyacrylamide gel electrophoresis (SDS-PAGE) and western blotting analyses of flocs

A floc sample $(5 \mu \mathrm{L})$ was subjected to SDS-PAGE. For western blotting, proteins were transferred from the gel to a membrane sheet of Hybond P (GE Healthcare Ltd., UK) 
1 using the semi-dry transfer method. Hybridization was conducted using an anti-GFP

2 primary antibody (Medical \& Biological Laboratories Co., Japan) and an ECL Western

3 Blotting Starter Kit (GE Healthcare Ltd.) according to the manufacturers' protocols.

4 Hybridization signals were detected using a ChemiDoc imaging system (Bio-Rad

5 Laboratories Inc., Hercules, CA).

6 The protein bands were analyzed by densitometry (Image J software; NIH, Bethesda,

7 MD) as an index of target protein expression. The amounts of GFP and Tsf-GFP were 8 determined using purified GFP and Tsf-GFP as standards. Purification of GFP and

9 Tsf-GFP was conducted using a Bio-scale Mini Profinity IMAC cartridge and Profinia protein purification system (Bio-Rad Laboratories Inc.) after ultrasonication of E. coli cells expressing each protein. Finally, the percentages of GFP and Tsf-GFP were determined based on total floc protein determined by the BCA method.

\section{RESULTS AND DISCUSSION}

\section{Flocculation of $E$. coli cells}

In our previous study, we confirmed floc formation of $E$. coli BW25113/bcs $B$ cells

[]. In this study, we also observed the flocculation of E. coli BW25113/bcsB/gfp and BW25113/bcsB/tsf-gfp cells (Fig. 1A). The flocs formed by these cells were approximately $1-2 \mathrm{~mm}$ and similar to those formed by BW25113/bcsB cells. Observations under black light irradiation showed that the flocs of BW25113/bcs $B / g f p$ and BW25113/bcsB/tsf-gfp cells produced green fluorescence (Fig. 1A), suggesting that the flocs included GFP within their structure. In particular, the intensity of green fluorescence in flocs formed by BW25113/bcsB/tsf-gfp cells was stronger than that in flocs formed by BW25113/bcsB/gfp cells. 
1 Next, the amount of protein in flocs was determined by the BCA method. In our

2 previous study, it was confirmed that the main components of $E$. coli flocs were

3 proteinous, and determination of the protein concentration could be used as an index for

4 the amount of flocs [13]. Compared with BW25113/bcsB cells $(320 \mathrm{mg} / \mathrm{L})$, the amounts

5 of floc proteins from BW25113/bcsB/gfp and BW25113/bcsB/tsf-gfp cells were 260 and

$6270 \mathrm{mg} / \mathrm{L}$, respectively. There was no significant adverse effect of GFP or Tsf-GFP

7 expression on the floc formation of BW25113/bcsB cells (Fig. 1B). Furthermore, the

8 number of cells per unit weight of floc protein was estimated by the ATP content and

9 compared among each strain. As shown in Fig. 1C, the numbers of BW25113/bcsB, BW25113/bcsB/gfp, and BW25113/bcsB/tsf-gfp cells included in the flocs were about $1.2 \times 10^{8}, 1.2 \times 10^{8}$ and $1.4 \times 10^{8}$ cells/mg-floc protein, respectively, suggesting that expression of GFP or Tsf-GFP did not affect the cell density within the floc structure. Thus, GFP and Tsf-GFP were successfully expressed without a negative effect on the properties of flocs, such as formation efficiency and cell inclusion. As for the reason why the expression of Tsf-GFP did not affect the properties of flocs, it is thought that the native Tsf protein contributes to maintaining the properties of flocs. In this study, we used the wild type strain as a host instead of $t s f$-deficient mutant strain since $t s f$ is known as an essential gene in E. coli cells [14]. Therefore, BW25113/bcsB/tsf-gfp cells express both native Tsf and recombinant Tsf-GFP. It can be speculated that the expression of native Tsf assists oligomerization of recombinant Tsf-GFP into the self-produced flocs while keeping the state of cells and properties of flocs.

\section{Observation of flocs}


Figure 2 shows images of typical flocs formed by respective E. coli strains. In the case of the BW25113/bcsB strain, optical microscopy showed fibrous structures on the surfaces of flocs (see bright field image in Fig. 2). Additionally, three-dimensional images obtained by confocal scanning laser microscopy (CLSM) revealed that PI-labeled E. coli cells were dispersed within the floc structure. Considering that the flocs were washed several times with saline solution before observation, it can be speculated that the E. coli cells are firmly bound to the flocs. These results also support our previous study indicating that flocs mainly contain polymer fibers rather than cell aggregates []. As expected, flocs formed by BW25113/bcsB cells did not show any green fluorescence because of the lack of GFP introduction (Fig. 2A). In the case of flocs formed by BW25113/bcsB/gfp cells (Fig. 2B), green fluorescence was scattered in spots within the floc structure. The spots of PI-labeled E. coli cells were overlapped with green fluorescence, suggesting that GFP was expressed within the cytoplasm of individual E. coli cells. In the case of BW25113/bcsB/tsf-gfp cells (Fig. 2C), the PI-labeled E. coli cells were also dispersed within the floc structure similarly to the cases of the other two strains. However, it is worth noting that green fluorescence was observed throughout the whole floc structure, even in spaces without PI-labeled cells. These observations support our strategy of displaying Tsf-GFP on the floc structure for secretion from E. coli cells, as expected based on our previous results showing that the floc component was largely Tsf protein.

\section{Quantitative evaluation of GFP and Tsf-GFP within the floc structure}

To determine the amounts of GFP and Tsf-GFP within the floc structure, the proteins in flocs were analyzed by western blotting. For comparison, the flocs were separated 
1 from suspended cells by sedimentation and each fraction was analyzed by western

2 blotting. The fraction of flocs still included cells trapped inside the floc structure. As

3 shown in Fig. 3A, in the case of BW25113/bcsB/gfp cells, calibration analysis using

4 purified GFP produced a clear single band at around $29 \mathrm{kDa}$, as predicted by the

5 molecular weight of GFP plus the additional sequence, and showed load dependency

6 (Fig. 3A). Samples from both flocs and cells also showed the band at around $29 \mathrm{kDa}$.

7 There was no significant difference in the amount of GFP between flocs and cells.

8 Conversely, in the case of the BW25113/bcsB/tsf-gfp strain, the bands in the calibration

9 analysis of purified Tsf-GFP appeared at around $75 \mathrm{kDa}$ that was larger than expected

10 molecular weight of the fusion protein $(60 \mathrm{kDa})$. The cell sample produced a single weak band at $75 \mathrm{kDa}$, whereas bands of the floc sample appeared at around both 60 and $75 \mathrm{kDa}$. This split of the band could not be improved by experimental modifications. It can be speculated that some Tsf-GFP molecules in the calibration samples and cell culture samples might not be denatured completely by SDS-treatment and appeared at lager size in the electrophoresis.

Next, GFP and Tsf-GFP were quantitatively analyzed by densitometry of the bands. In the case of Tsf-GFP in flocs, the band split at both 60 and $75 \mathrm{kDa}$. Therefore, two types of data were calculated. One only estimated the band at $75 \mathrm{kDa}$, and the other estimated both bands as the whole quantity. Fig. 3B shows the percentage of target protein in total cell proteins or total floc proteins. In the case of BW25113/bcsB/gfp strain, the percentage of GFP in cells and flocs were $2.2 \pm 0.6 \%(\mathrm{w} / \mathrm{w})$ and $2.5 \pm 0.9 \%$ (w/w), respectively. There was no significant difference. In contrast, as for BW25113/bcsB/tsf-gfp strain, whereas the percentage of Tsf-GFP in cells was $0.6 \pm 0.4 \%$

$24(\mathrm{w} / \mathrm{w})$, the values in flocs with and without including the band at $60 \mathrm{kDa}$ were 
$14.8 \pm 7.3 \%(\mathrm{w} / \mathrm{w})$ and $7.6 \pm 3.2 \%(\mathrm{w} / \mathrm{w})$, respectively. Considering that the number of

2 cells per unit weight of floc proteins was not significantly different in these flocs (Fig.

3 1C), the increase in the percentage was not due to the increase of cells within the floc 4 structure. Therefore, these results strongly support the view that Tsf-GFP was 5 transferred from E. coli cells to the whole floc structure.

6 We showed that the Tsf-GFP fusion protein was expressed throughout the whole floc

7 structure. In our previous report, Tsf protein had the highest score in NanoLC-MS/MS

8 analysis of floc proteins. Tsf is an elongation factor that promotes the release of GDP by

9 forming an intermediate complex with another elongation factor, $\mathrm{Tu}$, which is involved

10 in the elongation cycle of protein biosynthesis [9]. Tsf has been also identified as an aggregation-resistant protein by E. coli proteome-wide analysis in response to a protein denaturant [15]. The synthesis of soluble Tsf was significantly increased even under a strong protein-denaturing environment induced by guanidine hydrochloride. Compared with direct expression, various heterologous proteins are solubly expressed in E. coli when subjected to N-terminus fusions with Tsf [15-17]. Thus, Tsf appears to play critical roles in not only the elongation cycle of protein biosynthesis, but also sequencing interactive surfaces of heterologous proteins from nonspecific protein-protein interactions leading to the formation of inclusion bodies. Even though there is a gap between these reported functions of Tsf and the appearance of Tsf on proteinous $E$. coli flocs, our results demonstrated that the design of a fusion protein with Tsf enables displaying a recombinant target protein on the floc structure. Interestingly, the percentage of Tsf-GFP in total floc protein reached approximately $15 \%(\mathrm{w} / \mathrm{w})$.

To date, many studies have been focusing on the mechanism of microbial flocculation or control of flocculation in terms of external factor such as culture conditions and kind 
1 of flocculants [18]. However, the functionalization of flocs based on the gene

2 modification of microbes has not been reported. In particular, in the case of E. coli, the

3 forced flocculation by adding the flocculants was exclusively reported [ $\underline{3}, \underline{4}]$. Therefore,

4 our findings of spontaneous floc formation of $E$. coli and further functionalization by

5 displaying the recombinant protein on the floc structure will give a new concept for the

6 engineering and application of microbial flocs.

7

8 ACKNOWLEDGMENTS

9 This work was supported by a Grant-in-Aid for Young Scientists (B) (No. $1015 \mathrm{~K} 18275)$ from the Ministry of Education, Culture, Sports, Science and Technology of

11 Japan. This work was also supported by Chemical Innovation Encouragement Prize 12 from Japan Association for Chemical Innovation.

14 REFERENCES

[1] Salehizadeh H, Shojaosadati SA. Extracellular biopolymeric flocculants. Recent trends and biotechnological importance. Biotechnol Adv 2001;19:371-385.

[2] Tago Y, Aida K. Exocellular mucopolysaccharide closely related to bacterial floc formation. Appl Environ Microbiol 1977;34:308-314.

[3] Rehn G, Grey C, Branneby C, Adlercreutz P. Chitosan flocculation: an effective method for immobilization of E. coli for biocatalytic processes. J Biotechnol 2013;165:138-144.

[4] Yang Z, Degorce-Dumas JR, Yang H, Guibal E, Li A, Cheng R. Flocculation of Escherichia coli using a quaternary ammonium salt grafted carboxymethyl chitosan flocculant. Environ Sci Technol 2014;48:6867-6873. 
1 [5] Liu T, Yamashita K, Fukumoto Y, Tachibana T, Azuma M. Flocculation of real

$2 \quad$ sewage sludge using polyglutamic acid produced by Bacillus sp. isolated from soil. J

$3 \quad$ Chem Eng Jpn 2017;50:201-206.

4 [6] Nguyen MH, Ojima Y, Sakka M, Sakka K, Taya M. Probing of exopolysaccharides

5 with green fluorescence protein-labeled carbohydrate-binding module in Escherichia

$6 \quad$ coli biofilms and flocs induced by $b \operatorname{cs} B$ overexpression. J Biosci Bioeng

$7 \quad 2014 ; 118: 400-405$.

8 [7] Omadjela O, Narahari A, Strumillo J, Melida H, Mazur O, Bulone V, Zimmer J.

$9 \quad \mathrm{BcsA}$ and $\mathrm{BcsB}$ form the catalytically active core of bacterial cellulose synthase

10 sufficient for in vitro cellulose synthesis. Proc Natl Acad Sci U S A

$11 \quad 2013 ; 110: 17856-61$.

[8] Ojima Y, Nguyen MH, Yajima R, Taya M. Flocculation of Escherichia coli cells in association with enhanced production of outer membrane vesicles. Appl Environ Microbiol 2015;81:5900-5906.

[9] Zhang Y, Sun V, Spremulli LL. Role of domains in Escherichia coli and mammalian 16 mitochondrial elongation factor Ts in the interaction with elongation factor Tu. J Biol $17 \quad$ Chem 1997;272:21956-21963.

[10] Baba T, Ara T, Hasegawa M, Takai Y, Okumura Y, Baba M, Datsenko KA, Tomita M, Wanner BL, Mori H. Construction of Escherichia coli K-12 in-frame, single-gene knockout mutants: The Keio collection. Mol Syst Biol 2006;2:2006.0008.

[11] Saka K, Tadenuma M, Nakade S, Tanaka N, Sugawara H, Nishikawa K, Ichiyoshi coli open reading frames in mobile plasmids facilitating genetic studies. DNA Res 2005; 12:63-68. 
1 [12] Kitagawa M, Ara T, Arifuzzaman M, Ioka-Nakamichi T, Inamoto E, Toyonaga H,

2 Mori H. Complete set of ORF clones of Escherichia coli ASKA library (a complete

3 set of E. coli $\mathrm{K}-12$ ORF archive): Unique resources for biological research. DNA Res

$4 \quad 2005 ; 12: 291-299$.

5 [13] Ojima Y, Takeda S, Taya M. Floc formation of ethnaol producing Escherichia coli

$6 \quad$ KO11 cells and its application to repeated batch operation. J Chem Eng Jpn

$7 \quad 2016 ; 49: 793-798$.

8 [14] Gerdes SY, Scholle MD, Campbell JW, Balazsi G, Ravasz E, Daugherty MD,

9 Somera AL, Kyrpides NC, Anderson I, Gelfand MS, Bhattacharya A, Kapatral V,

10 D'Souza M, Baev MV, Grechkin Y, Mseeh F, Fonstein MY, Overbeek R, Barabasi AL,

11 Oltvai ZN, Osterman AL. Experimental determination and system level analysis of

12 essential genes in Escherichia coli MG1655. J Bacteriol 2003;185:5673-5684.

13 [15] Han KY, Song JA, Ahn KY, Park JS, Seo HS, Lee J. Enhanced solubility of

14 heterologous proteins by fusion expression using stress-induced Escherichia coli

15 protein, Tsf. FEMS Microbiol Lett 2007;274:132-138.

16 [16] Maffitt M, Auldridge M, Sen S, Floyd S, Krerowicz A, Uphoff M, Thompson J,

17 Mead D, Steinmetz E. Rapid screening for protein solubility and expression. Nat

18 Meth 2015;12:1-2.

19 [17] Ahn KY, Lee B, Han KY, Song JA, Lee DS, Lee J. Synthesis of Mycoplasma

20 arginine deiminase in E. coli using stress-responsive proteins. Enzyme Microb

$21 \quad$ Technol 2014;63:46-49.

22

[18] Jia BJ, Yu JM. The research status and development trend of microbial flocculant.

23 Phys Procedia 2012;24:425-428.

24 
FIGURE LEGENDS

2 Fig. 1 Floc formation of $E$. coli BW25113/bcsB, BW25113/bcsB/gfp and

3

4

5

6

9

(A)

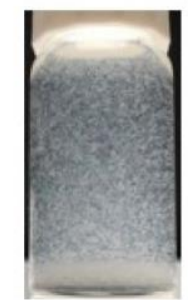

BW25113/ bcsB
FL irradiation

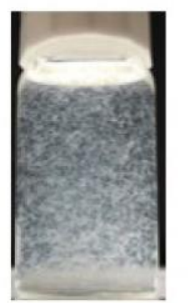

BW25113/ bcsB/gfp

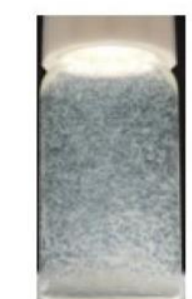

BW25113/ bcsBltsf-gfp

. (A) Image of E. coli floc suspensions irradiated under fluorescent light (FL) or black light (BL) lamps. The flocs were harvested at $24 \mathrm{~h}$ of culture. (B) Floc protein concentration of each E. coli strain. (C) Cell number of each E. coli strain included in flocs. In graphs (B) and (C), data were

(B)

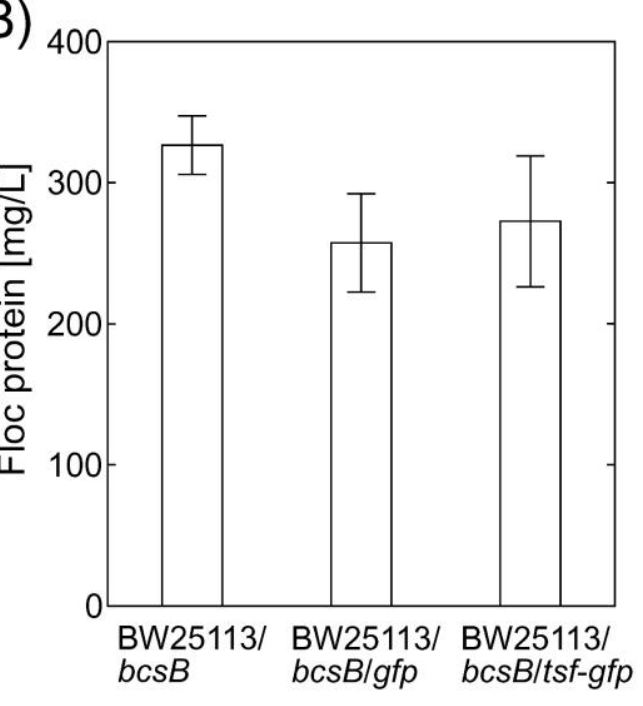

BL irradiation

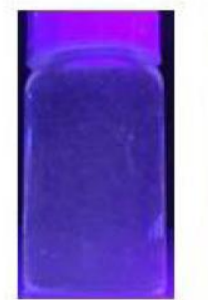

BW25113/

$\begin{array}{ll}\text { BW25113/ } & \text { BW25113/ } \\ \text { bcsBlgfp } & \text { bcsB/tsf-gfp }\end{array}$

(C)

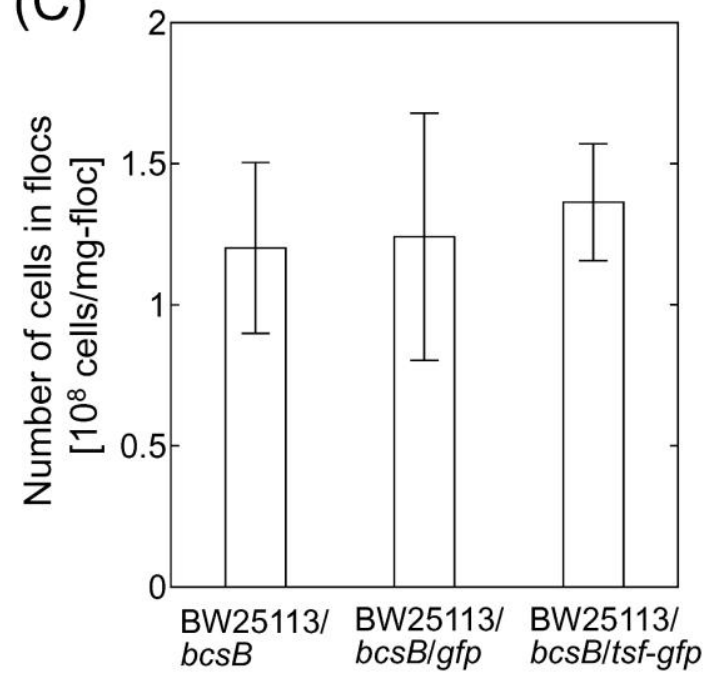


1 Fig. 2 CLSM images of flocs formed by E. coli BW25113/bcsB, BW25113/bcsB/gfp

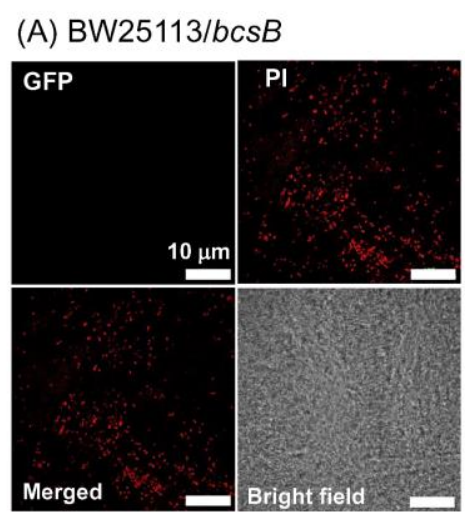

(B) BW25113/bcsB/gfp

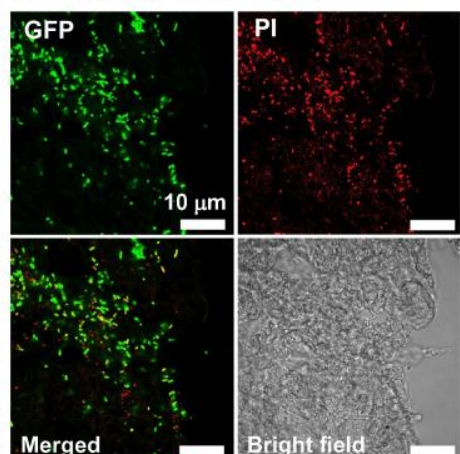

(C) BW25113/bcsB/tsf-gfp

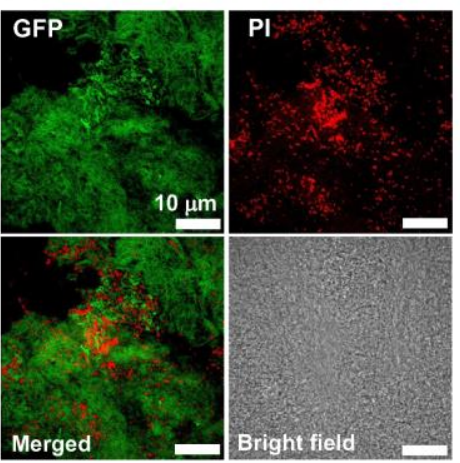
floc structure, and DNA as a whole bacterial cell's indicator (red) was stained with PI.

6 and BW25113/bcsB/tsf-gfp strains. GFP (green) visualized localization in the 
1 Fig. 3 Quantification of recombinant proteins expressed on/in flocs and cells of each

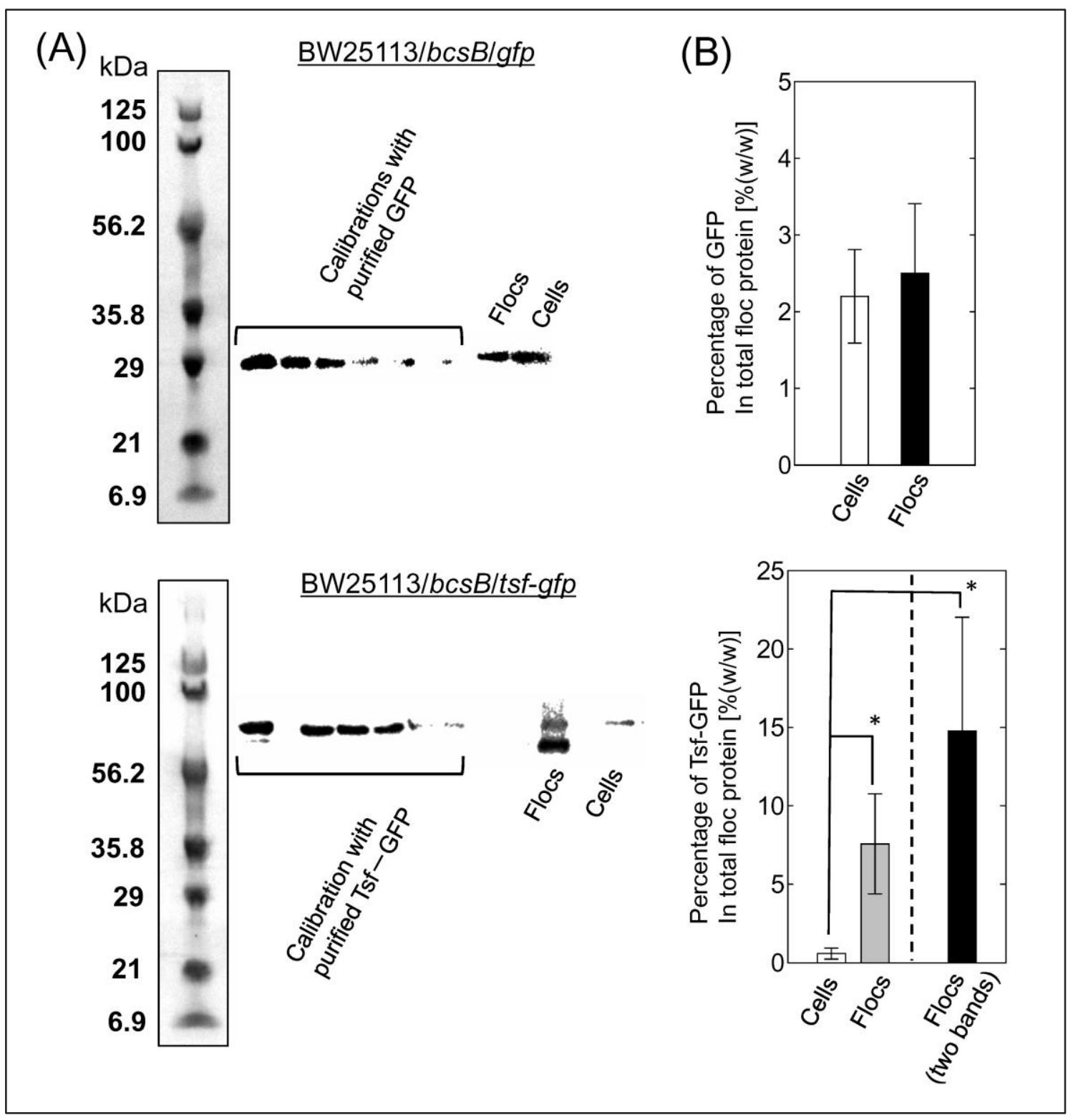


Table 1 E. coli strains and plasmids used in this study.

\begin{tabular}{|c|c|c|}
\hline Strains or plamisds & Note & Reference \\
\hline Strains & & \\
\hline BW25113 & Host strain of Keio collection & {$[10]$} \\
\hline Plasmids & & \\
\hline pNTR-SD- $b c s B$ & $\begin{array}{l}\text { pNTR-SD carrying } b c s B \text { under } \mathrm{P}_{\text {lac }} \\
\text { control, } \mathrm{Amp}^{\mathrm{r}}\end{array}$ & {$[11]$} \\
\hline pCA24N & $\mathrm{Cm}^{\mathrm{r}}$ & {$[12]$} \\
\hline pCA24N-gfp & $\begin{array}{l}\text { pCA24N carrying } g f p \text { under } \mathrm{P}_{\mathrm{T} 5-\mathrm{lac}} \\
\text { control, } \mathrm{Cm}^{\mathrm{r}}\end{array}$ & This study \\
\hline ASKA-tsf-gfp & $\begin{array}{l}\text { pCA24N carrying } t s f \text { and } g f p \text { under } \mathrm{P}_{\mathrm{T} 5-\mathrm{lac}} \\
\text { control, } \mathrm{Cm}^{\mathrm{r}}\end{array}$ & {$[12]$} \\
\hline
\end{tabular}

